
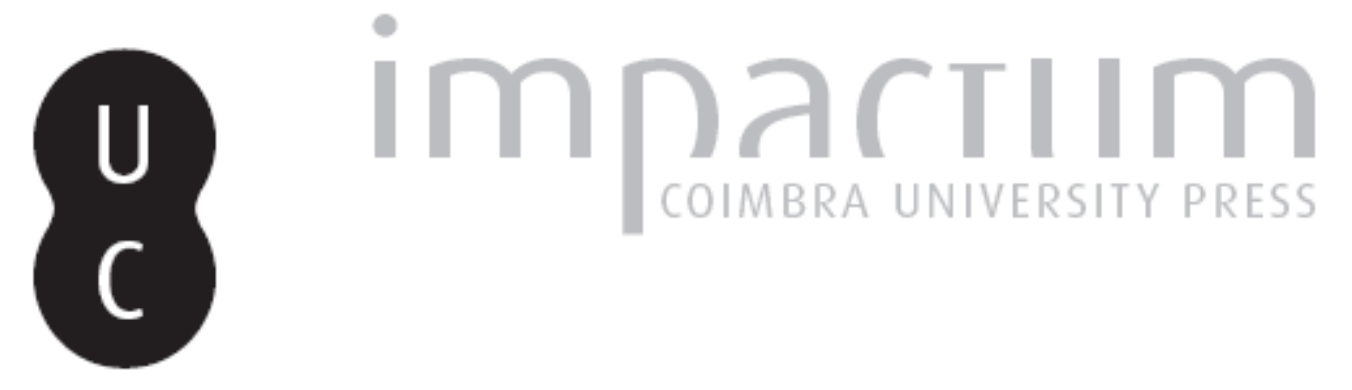

\title{
Caracterológico e atmosférico dos processos proto-semiósicos fisiognómicos
}

Autor(es): Braga, Joaquim

Publicado por: Imprensa da Universidade de Coimbra

URL persistente:

URI:http://hdl.handle.net/10316.2/35504

DOI:

DOI:http://dx.doi.org/10.14195/0870-4112_11_8

Accessed : $\quad$ 26-Apr-2023 15:42:25

A navegação consulta e descarregamento dos títulos inseridos nas Bibliotecas Digitais UC Digitalis, UC Pombalina e UC Impactum, pressupõem a aceitação plena e sem reservas dos Termos e Condições de Uso destas Bibliotecas Digitais, disponíveis em https://digitalis.uc.pt/pt-pt/termos.

Conforme exposto nos referidos Termos e Condições de Uso, o descarregamento de títulos de acesso restrito requer uma licença válida de autorização devendo o utilizador aceder ao(s) documento(s) a partir de um endereço de IP da instituição detentora da supramencionada licença.

Ao utilizador é apenas permitido o descarregamento para uso pessoal, pelo que o emprego do(s) título(s) descarregado(s) para outro fim, designadamente comercial, carece de autorização do respetivo autor ou editor da obra.

Na medida em que todas as obras da UC Digitalis se encontram protegidas pelo Código do Direito de Autor e Direitos Conexos e demais legislação aplicável, toda a cópia, parcial ou total, deste documento, nos casos em que é legalmente admitida, deverá conter ou fazer-se acompanhar por este aviso.

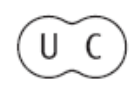




\section{ESTÉTICA E POLÍTICA}

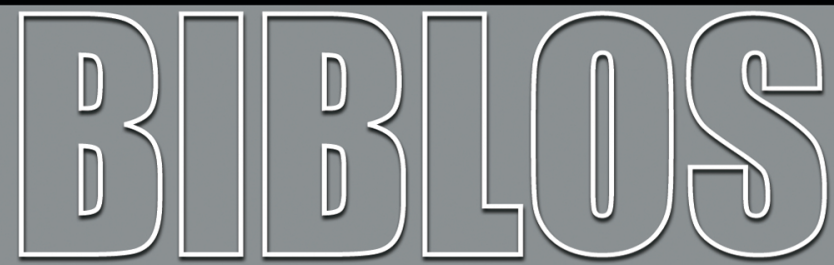

REVISTA DA FACULDADE DE LETRAS UNIVERSIDADE DE COIMBRA 
Biblos, n. s. XI (2013) 233-250

DOI: http://dx.doi.org/10.14195/0870-4112_11_8

JOAQUim BRAGA

Unidade I\&D LIF, Faculdade de Letras da Universidade de Coimbra

Bolseiro da FCT

\title{
CARACTEROLÓGICO E ATMOSFÉRICO DOS PROCESSOS PROTO-SEMIÓSICOS FISIOGNÓMICOS
}

\section{Resumo}

O conceito de "fisiognómico" é, ainda hoje, marcado por uma grande ambiguidade semântica, ao ponto de, muitas vezes, ser excluído da reflexão sobre o estético. Uma das razões desta exclusão reside, sobretudo, na sua genealogia ideológica, que, como se verá neste texto, se confunde com a sua genealogia estética. Há, porém, um percurso individuante do fisiognómico cujas dimensões se inscrevem na descoberta da autonomia da sensibilidade estético-artística, bem como na redefinição teórica da natureza dos processos semiósicos. Estas duas dimensões dão corpo à reflexão que aqui se apresenta.

Palavras-chave: fisiognómico, carácter, ideológico, atmosférico, estética.

\begin{abstract}
The concept of "physiognomic" is still marked by a large semantic ambiguity, to the point of being often excluded from aesthetic thought. One reason for this exclusion lies primarily in its ideological genealogy, which, as we will see in this text, is connected with its aesthetic genealogy. There is, however, a physiognomic individuating trajectory whose dimensions are present in the discovery of the autonomy of aesthetic-artistic sensibility as well as in the theoretical redefinition of the nature of semiosic processes. Both dimensions are inscribed in the reflections presented here.
\end{abstract}

Keywords: physiognomic, character, ideological, atmospheric, aesthetics. 


\section{Introdução}

Mostra-nos a nossa experiência quotidiana do mundo que a atenção votada a certos objectos e eventos físicos raramente é desprovida de "primeiras impressões", cujas propriedades nos podem sugerir ora uma maior disponibilidade psíquica para retê-los dentro do nosso campo de observação ou, pelo contrário, um total desinteresse (ou mesmo aversão) cognitivo pelas suas qualidades sensíveis. Ter a primeira impressão de algo nem sempre implica, pois, dar tempo ao seu conhecimento. E outras situações há em que a primeira permanece como última impressão, parecendo indiciar um lapso temporal cognitivo entre observador e observado. Não raras vezes delas dizemos que foram "violentas", apesar de poderem ter sido emocionalmente gratificantes, como nos casos de empatia amorosa.

O que estes factos da e na vida da percepção nos revelam é, antes de tudo, a função activa da sensibilidade nos processos de selecção de possibilidades de sentido. Mas, e indo um pouco mais longe, a isso se pode acrescentar a ideia de que esses mesmos factos, essas impressões, também operam como potenciadores das dimensões sensíveis com que enriquecemos os fenómenos da percepção. Facilmente este último ponto se deixa associar aos fenómenos estético-artísticos. E por várias razões. Uma delas - talvez a mais significativa - reside no princípio geral de a arte, enquanto forma simbólica, preservar a sua autonomia graças a uma constante revitalização da sensibilidade. Estilos artísticos transportam, nesse aspecto, autênticas propostas de auscultação e redefinição do sensível que a arte deve emprestar aos seus objectos. Independentemente da profusão de estilos, a arte moderna encetou um percurso estético que pode ser descrito, a um tempo, como expansão e deslocação da sensibilidade. "Expansão" relativamente ao campo da percepção, que se revela cada vez mais dilatado, dado a obra de arte se oferecer como imanência sensível e ser susceptível de uma pregnância de sentido polissémica. "Deslocação" porque com a expansão da esfera da sensibilidade deixa de ser possível pensar a Aisthesis apenas a partir dos eixos gravitacionais da obra de arte, bem como dos limites categoriais de uma contemplação orientada pelo belo. Resumindo estes dois movimentos: a experiência perceptiva mediada pela obra promove uma verdadeira expropriação do estético, remetendo-o não só para a observação dos fenómenos 
da natureza - um dos horizontes intra-artísticos da estética clássica - como também para os fenómenos mais elementares da vida quotidiana, psíquicos ou sociais.

Reconhecer a tensão entre sensibilidade e conhecimento, entre acontecimento perceptivo e discernimento cognitivo, é, pois, um acto que trespassa a actividade artística moderna, bem como a sua própria análise teórica. A Aisthesis vê-se assim confrontada com a natureza contrastante e individuante do mundo sensível, desligando-se, cada vez mais, da convergência comummente imposta entre as esferas da sensibilidade e as da moralidade. Por via desta tensão, do repto lançado à percepção redunda, igualmente, a configuração da obra de arte mediante articuladores de sentido que se opõem radicalmente aos dos fenómenos estáveis da nossa percepção quotidiana. Mas este facto não implica pressupor que a apreensão estético-artística suprime totalmente a apreensão sensível da percepção, já que a primeira se afigura como expansão e transformação operatórias da segunda. A arte moderna, ao impor, gradualmente, um primado da sensibilidade sobre a imaginação - ao ponto de esta última ser elevada à condição de imaginação sensível -, confere uma nova vida às operações de sentido alicerçadas na percepção. Se a imaginação teve como seu correlato expressivo artístico a ficção, já a sensibilidade vem requer da obra de arte a expansão das vivências sensoriais. Contudo, tal primado não se verifica apenas no campo perceptual. Há, no campo comunicacional do sistema artístico, nomeadamente ao nível das descrições sobre a obra de arte, um uso da imaginação ao serviço da recriação da esfera individualizada da sensibilidade. A imaginatio tende a servir o perceptum quando se efectiva o deslocamento da imaginação fictiva para a imaginação descritiva.

Por acuidade teórica, a depreensão da autonomia da sensibilidade passa pelo reconhecimento da autonomia semiósica do significante. E é, precisamente, a descoberta desta autonomia que põe em jogo as modalidades perceptuais que antecedem o binómio "significante-significado". Reservamos, por isso, a expressão "proto-semiósicos" para especializar os processos do qual fazem parte tais modalidades - que, ao nível da semiosis, podem ser compreendidas como formas primárias que antecedem o modelo de substituição aplicado, em geral, pela semiótica de inspiração saussureana à teoria dos signos. 


\section{Percepção e bipolarização}

Da arte moderna herdámos a ideia de um primado estético do "significante" sobre o "significado"; herança árdua para a reflexão teórica, uma vez que os processos semiósicos concernentes ao representacionalismo estético tinham como principal ponto de partida uma linear articulação de ambos e, em muitos casos, uma total submissão do significante ao significado. Mas se, ao nível das categorias da representação, o equilíbrio funcional dos dois não suscitou grande questionamento teórico, já tal não parece suceder com o "desequilíbrio" fomentado pelo primado do significante. A configuração do significante põe em jogo a natureza configuradora da sensibilidade. Daí que o questionamento surja, precisamente, quando nos interrogamos sobre as potencialidades da vida perceptiva que tornam esse primado possível.

Atribuir ao objecto artístico a capacidade estética de gerar eixos de sentido sem hipotecar a sua materialidade individual, pressupõe, antes de tudo, atribuir-lhe uma esfera íntima, uma vida própria. Por outro lado, o primado do significante não traz somente à expressão a individualidade do objecto artístico. Paralelamente é a vida perceptiva do sujeito que, emancipado da função de intérprete do significado do objecto, se depara com uma maior autonomia psíquica face aos jogos comunicacionais que se estabelecem em torno do sistema artístico. A mesma dupla individuação de obra e espectador pode ser inferida do discurso do artista moderno. Paul Cézanne, por exemplo, faz da autonomia psíquica do pintor e da autonomia material dos elementos pictóricos uma articulação permanente dentro dos processos de criação. Nestes, a dupla individuação é expressa por Cézanne da seguinte forma: «Quando pinto, não penso em nada, apenas vejo cores, que se organizam espontaneamente» ${ }^{1}$. Criação e materialização artísticas servem agora a edificação do primado do significante, ao ponto de a intencionalidade autoral ser sacrificada em prol de uma imediaticidade sensível cuja ordem espontânea assegura a ligação entre agente criador e objecto criado.

${ }^{1}$ CÉzanne, Paul, In: Dokumente zum Verständnis der modernen Malerei, Hrsg. Von Walter Hess, Hamburg, Rowohlt, 1956, pp. 16-21, p. 20. 
Sem que tenhamos de sair da asserção de Cézanne - porque ela é representativa dos caminhos trilhados pela pintura moderna, e a arte em geral -, é-nos possível inferir da emancipação da sensibilidade artística uma visão alargada sobre o mundo da percepção. Tal como Cézanne durante os processos de criação, também o espectador moderno se vê imerso nos objectos que contempla. Este facto vem sustentar e exemplificar a ideia de que as operações da percepção não podem ser reduzidas a meras articulações constativas através das quais o cognoscente toma consciência de uma entidade sensível. A coexistência de duas presenças distintas - a do sujeito e a do objecto - requer sempre um processo de diferenciação; mas, anteriormente à ocorrência desse processo, há um estádio perceptual - indexicálico, por assim dizer - que actualiza a co-presença sensível de cognoscente e cognoscível. É sabido que a consciência egológica depende, em parte, das relações mediadas pelo sentido entre cognoscente e cognoscível. O grau de diferenciação resultante da autonomia do eu face ao objecto alberga uma descontinuidade entre ambos. Porém, na base dos processos de diferenciação - que redundam numa tomada de consciência cada vez maior por parte do eu - existem níveis psíquicos reveladores de uma exígua bipolarização entre eu e objecto. Há, nestes casos da vida psíquica, formas vivenciais concrescentes que precedem e potenciam a descontinuidade traçada pela bipolarização.

A concepção de eixos teóricos que façam jus à relevância da sensibilidade e à sua autonomia face às imposições sígnicas da representação encontra-se, por conseguinte, dependente de uma visão dos processos perceptivos que tenha em conta as suas propriedades semiósicas primárias (proto-semiósicas, na nossa acepção). Ao mesmo tempo que a linha de não-diferenciação entre sujeito e objecto é seguida, ganha forma a ideia de um potencial individuante da sensibilidade, cujo reflexo mais imediato se vislumbra no mundo gerado pela obra artística.

\section{Transparência e determinação}

Um dos maiores contributos teórico-conceptuais para a edificação da vida autónoma da sensibilidade - e, através dela, da própria expressão estético-artística - está ligado à reflexão em torno do conceito de "fisiognómico". Na sua fase inicial, a fisiognomia foi vista como uma 
ciência capaz de analisar e fixar, através de um vasto espectro de aparências físicas, a natureza psíquica dos indivíduos. Depressa a crença num essencialismo visual do carácter humano fez dela uma observação apoiada em formas imagéticas. A constituição de uma ciência fisiognómica foi o objectivo capital dos estudos empreendidos, no século XVIII, pelo teólogo suíço, Johann Caspar Lavater. Intentando transformar a investigação fisiognómica numa ciência exacta, baseada em leis causais, que a afastassem das explicações mitológicas clássicas, Lavater começará por opor o fisiognómico ao patognómico. No cerne da distinção proposta encontra-se a ideia de movimento. A ciência fisiognómica ocupar-se-ia das «interpretações de forças» (Kraftdeutung), dos sinais estáveis e invariáveis da energia espiritual (note-se, a este respeito, o nexo analógico entre "fisiognomia" e "fisionomia", nomeadamente ao nível do carácter estático das manifestações sensíveis). Já a ciência patognómica teria como principal função «interpretar as paixões», os sinais dinâmicos e variáveis das afecções da alma ${ }^{2}$. Se esta última via nas configurações faciais dinâmicas a expressão das paixões, já a primeira interpretava as configurações faciais estáticas como verdadeiras expressões do carácter. $\mathrm{O}$ estudo fisiognómico é, neste sentido, uma autêntica "caracterologia", capaz de trazer à expressão a fisiognomia nacional de certos povos. ${ }^{3}$

Ao nível da expressão autoral artística, uma semiose caracterológica assenta no pressuposto de uma osmose identitária entre o signo sensível (imagem, por exemplo) e a esfera psíquica do criador desse mesmo signo - isto é, o carácter exposto é o carácter imposto. Tal transparência sígnica não é sustentável sem uma concepção mimética da arte - a obra é signum naturalis. Para Lavater, a arte pictural é, a um tempo, «Mutter und Tochter der Physiognomik» ${ }^{4}$. "Mãe" porque a picturalidade ostenta

${ }^{2}$ LaVATER, J. C., Physiognomische Fragmente zur Beförderung der Menschenkenntniß 3 und Menschenliebe, Band 4, Leipzig, Verlag Heinrich Steiners und Compagnie, 1778 , p. 39.

${ }^{3}$ É neste intento de se traçar uma pretensa génese caracterológica nacional que Ernst Gombrich encontra a physiognomical fallacy. A falácia explica-se, segundo o teórico da arte, como «the myth that the system of signs, the style, is not a language but an utterance of the collective, in which a nation or age, speaks to us.» Gombrich, Ernst, "Art and Scholarship", In: College Art Journal, Vol. 17, No. 4 (Summer, 1958), pp. 342-356, p. 349.

${ }^{4}$ Lavater, J. C., Physiognomische Fragmente... Band 1, p. 70. 
um amplo espectro epistemológico de modalidades visuais que permitem o reconhecimento de traços fisiognómicos; "filha" porque, com o desenvolvimento da ciência fisiognómica, há nela uma ressonância teórica dos estudos sobre a arte.

Convém constatar, porém, que a transparência sígnica lavateriana é atravessada por uma redução epistemológica do visual. Intentando uma purificação caracterológica do psiquismo humano, o teólogo suíço verá na "silhueta" o meio visual mais ajustado para o estudo do fisiognómico. O esquematismo silhuético opera uma redução visual na representação da figura humana, suspende a sua dinâmica icónica expressiva. (Esta estratégia da redução visual pode ser encontrada em William Hogarth. Também ele delineou, através da sua line of beauty, isolar, visualmente, a expressão autêntica do belo. ${ }^{5}$ ) A ausência de «movimento», de «luz» ou «cor» faz da silhueta um instrumento indispensável para a observação do carácter $^{6}$. E é por isso, precisamente, que a silhueta se consagra como uma forma eficaz de aceder à essência autêntica - porque visualmente imutável - do psiquismo humano. A repercussão desta pretensão inscreveu-se em várias manifestações estéticas. Nalgumas obras cinematográficas, principalmente naquelas em que a narrativa é construída a partir do código herói-vilão, há uma concordância excessivamente caracterológica entre o retrato psicológico das personagens e a sua moldura física - o vilão não pratica apenas actos malévolos; ele tem de "parecer" maléfico. Esta ideia encontra-se já expressa na aisthesis moralis da ciência fisiognómica lavateriana: «Je moralisch besser, desto schöner. Je moralisch schlimmer, desto häßlicher.» ${ }^{7}$ A estética lavateriana contém, nessa exacta medida, dois correlatos morais centrais: o belo é a expressão da virtude; o feio é a expressão do vício.

É, ainda, recorrendo às formas cinematográficas que podemos encontrar uma nova extensão da pretensa correspondência caracterológica do fisiognómico. Para Béla Balázs, a máquina cinematográfica é aquele meio que, pela primeira vez, consegue redescobrir a natureza fisiognómica das entidades animadas e inanimadas. Principalmente estas últimas conquistam um "rosto" que ainda não possuíam. (Tendo

${ }^{5}$ Hogarth, William, The Analysis of Beauty, Edited with an Introduction and Notes by Ronald Paulson, New Haven \& London, Yale University Press, 1997.

${ }^{6}$ Lavater, J. C., Physiognomische Fragmente... Band 2, p. 108.

${ }^{7}$ Lavater, J. C., Physiognomische Fragmente... Band 1, p. 183. 
sido aluno de Georg Simmel, não é de estranhar a ênfase que ele confere ao rosto e à paisagem, elementos provenientes da análise fisiognómica efectuada por Simmel, que tem o conceito de Stimmung como seu eixo central.) Balázs, ao eleger o rosto humano como a grande configuração cinematográfica, graças à técnica do close-up, reduz o fisiognómico a um "microfisiognómico". A estratégia da redução visual presente no primado das formas silhuéticas nas investigações lavaterianas ganha, aqui, com os mecanismos de focagem da cine-máquina, um novo fôlego caracterológico. Mas as afinidades com a ciência fisiognómica lavateriana não cessam neste ponto da redução. Similarmente ao uso que Lavater faz da pintura, também Balázs propõe que os conteúdos visuais das imagens cinematográficas sejam utilizados para a edificação de uma ciência - comparativa - que se ocupe da investigação dos traços gerais da expressão facial. Embora reconheça a dificuldade de se apurar uma correspondência exacta entre rostidade e nacionalidade $^{8}$, ele não deixará de declarar que «one of the tasks of the film is to show us, by means of 'microphysiognomics', how much of what is in our faces is our own and how much of it is the common property of our family, nation or class.» ${ }^{9}$ A crítica de Gombrich da "falácia fisiognómica" aplica-se, de forma assertiva, a esta aspiração ideológica de Balázs, muito embora as implicações do legado do teórico húngaro não devam ser vistas somente sob o prisma de um nacionalismo icónico.

A ciência fisiognómica pretende, pois, ultrapassar o hiatus semiótico entre significante e significado, fundado pela arbitrariedade impregnada na sua articulação; intenção esta, porém, que se distancia liminarmente do caminho encetado pela Modernidade. Coube à estética moderna estabelecer fundamentos teóricos válidos para a premissa de que as vivências sensíveis de cada indivíduo se diferenciam das suas inscrições em formas de mediação artificiais, isto é, extra-psíquicas. Da diferença introduzida entre percepção e expressão, entre consciência e comunicação, redunda a ideia de "intraduzibilidade psíquica", que nos sugere a impossibilidade de o facto da percepção ser reduzido ao facto da comunicação. Tal distinção possa ser já encontrada na crítica assertiva de Georg Wilhelm Friedrich Hegel às pretensões da pseudo-

${ }^{8}$ BALÁzs, Béla, Theory of the Film. Character and growth of a new art, London, Dennis Dobson, 1931, p. 81.

${ }^{9}$ Ibidem, p. 83. 
-ciência fisiognómica. Rejeitando as teorias da mente expressivistas, Hegel designa o objecto da ciência fisiognómica como totes Ding ${ }^{10}$, já que este nada pode revelar da consciência de cada indivíduo. Pelo contrário, as aparências físicas - aquilo a que os defensores da pseudo-ciência querem chamar de "traços" do carácter - têm uma natureza puramente deceptiva. Por outro lado - e ainda graças à estética moderna -, ganhou igualmente forma um conceito de comunicação através do qual nos é possível compreender a autonomia sistémica das esferas do social. Este último aspecto mostra-nos, precisamente, que a estética está longe de ser apenas uma compreensão teórico-conceptual das manifestações artísticas. Ela é, igualmente, um ponto de observação central dos mecanismos auto-referenciais que dão forma às operações da comunicação. Com efeito, o substrato ideológico presente nas aspirações da fisiognomia como ciência empírica justifica-se, em parte, pela tentativa de debelar a intraduzibilidade psíquica de cada indivíduo, bem como pela imposição de um conector identitário - isto é, não-diferencial entre consciência e expressão. É, também, dessa maneira que o lapso semiósico entre significante e significado deixa de poder ser inscrito nas operações mediadas pelo sentido; estas, pelo contrário, são substancializadas (o mesmo é dizer: naturalizadas) pelo ideológico.

\section{Opacidade e indeterminação}

A evolução semântica do conceito de "fisiognómico" mostra-nos, por conseguinte, num primeiro momento, um estádio ideológico, em que a picturalidade figurativa está ao serviço de uma retórica caracterológica - em muitos casos, retórica eugénica -, e, num segundo momento, um estádio propriamente estético, alicerçado na autonomia das formas pictóricas artísticas. Esta ambiguidade semântico-teórica do fisiognómico justifica-se, em parte, pelo facto de a percepção não se encontrar ainda envolvida em operações semiósicas diferenciadas - e que, potencialmente, podem redundar na distinção categorial entre significante e significado. Trata-se, em rigor, de uma opacidade semiósica.

${ }^{10}$ Hegel, G. W. F., Phänomenologie des Geistes, Frankfurt am Main, Suhrkamp Verlag, 2. Aufl., 1989, p. 129. 
A “indistinção" é entendida por muitos teóricos apenas como um fenómeno cognitivo regressivo. Insistindo na crítica da "falácia fisiognómica", Gombrich, por exemplo, vê no fisiognómico uma «regressão», que se opõe a uma «compreensão» diferenciada da obra de arte. Apesar de achar que o mundo artístico também tem por função mostrar os caminhos da regressão (indistinção), contra um mundo cada vez mais especializado, Gombrich não defende um primado do fisiognómico na esfera estético-artística. Pelo contrário: «The physiognomic approach may lead to the suicide of criticism» ${ }^{11}$. Em parte, esta preocupação não deixa de ser legítima. A transposição discursiva do fisiognómico esteve, desde sempre, associada a descrições sobre a obra de arte que tendiam a fazer desta um mero receptáculo de inscrições etnográficas e comparativas, ao ponto da sua relevância estética ser inteiramente remetida para processos de identificação colectivos.

Uma concepção positiva da opacidade semiósica da percepção pode ser encontrada em Heinz Werner e Ernst Cassirer. Embora o primeiro tivesse sido aluno de Theodor Lipps, ele não vai seguir a teoria proposta por este último sobre as qualidades estéticas dos objectos artísticos. A teoria da "physiognomische Wahrnehmung" de Werner distingue-se, de forma inequívoca, da teoria da "Einfühlung" de Lipps. O conceito de Einfühlung pressupõe um processo de externalização subjectivo, cujo resultado imediato é a polarização entre sujeito cognoscente e objecto cognoscível. A ideia de projecção, contida neste processo, conduz a uma visão das modalidades da percepção fisiognómicas como verdadeiras deformações de um pretenso carácter, originário e puro - isto é, não-fisiognómico -, das operações perceptivas. O antropomorfismo seria, neste caso específico, uma mera distorção fisiognómica. Um dos traços distintivos da proposta de Werner reside, justamente, em não tomar como ponto de partida apenas as operações de projecção psíquicas presentes no âmago teórico da aproximação empática. Com esta des-psicologização da sensibilidade pretende Werner mostrar que a percepção fisiognómica não se funda meramente sob uma base emotiva, mas antes sob as qualidades primárias da experiência sensível. As qualidades fisiognómicas são, nesta acepção, «the most primitive percep-

${ }^{11}$ Gombrich, Ernst, “On Physiognomic Perception”, In: Daedalus, Vol. 89, No. 1, The Visual Arts Today (Winter, 1960), pp. 228-241, p. 237. 
tions of all» $»^{12}$. Werner, ao resumir alguns dos estudos de Klaus Conrad sobre os fenómenos afásicos, dá-nos uma melhor compreensão desta sua concepção: «perception is global first, in contradistinction to a later stage at which the parts become increasingly more articulated and integrated with respect to the whole. Furthermore, much of the initial perceptual quality is dynamic, "physiognomic"; feeling and perceiving are little differentiated, imagining and perceiving not clearly separated.» ${ }^{13}$ Estas propriedades arqui-indiferenciadas da percepção operam, nesse sentido, como afirmação do "todo" face aos seus elementos contrastantes, que, para Werner, resultam quase sempre de um esvaziamento gradual das suas propriedades sensíveis.

Cassirer, tal como Werner, não interpreta o fisiognómico simplesmente como "regressão", mas antes como um ponto de partida através do qual as vivências da percepção começam por ser articuladas. ${ }^{14}$ Trata-se, aqui, de um impulso configurador que antecede as elaborações mais categoriais dos mecanismos perceptivos. Cassirer mostra-nos que os processos proto-semiósicos da percepção são indispensáveis para a constituição do sentido nas diversas esferas psíquicas e sócio-culturais do ser humano. Numa das suas exemplicações teóricas mais célebres a "linha ornamental", introduzida para servir de apoio à apresentação e clarificação do conceito de symbolische Prägnanz -, o filósofo adjec-

12 Werner, Heinz, "On physiognomic modes of perception and their experimental investigation”, In: S. S. Barten \& M. R. Franklin (Eds.), Developmental processes: Heinz Werner's selected writings, Volume 1, General theory and perceptual experience, New York, International Universities Press, 1978, pp. 149-167, p. 149.

${ }^{13}$ Werner, Heinz, "Microgenesis and Aphasia", In: The Journal of Abnormal and Social Psychology, Vol. 52(3), May 1956, pp. 347-353, p. 347.

${ }^{14}$ Cassirer, Ernst, Philosophie der symbolischen Formen, Dritter Teil: Phänomenologie der Erkenntnis, Darmstadt, Wissenschaftliche Buchgesellschaft, 10. Aufl., 1994, p. 95. É através da mesma linha teórica traçada por Cassirer e Werner que Rudolf Arnheim justifica a relevância estética das modalidades fisiognómicas: «The priority of physiognomic properties should not come as a surprise. Our senses are not self-contained recording devices operating for their own sake. They have been developed by the organism as an aid in properly reacting to the environment, and the organism is primarily interested in the forces that are active around it - their place, strength, direction». ARNHEIM, R., Art and visual perception: A psychology of the creative eye, Berkley, University of California Press, New version, expanded and rev., 2004, p. 455. 
tiva os processos perceptivos primários de "fisiognómicos". Antes de a linha ornamental activar na percepção modalidades de apreensão diferenciadas (mitológicas, religiosas, artísticas, científicas), há um nível, por assim dizer, pré-cognitivo, no qual se manifestam sensações indiscriminadas e, por isso mesmo, plenas de qualidades sensíveis e expressivas. ${ }^{15}$ Apesar disso, o autor da Philosophie der symbolischen Formen não priva o fisiognómico da sua ambiguidade teórica, mostrando, quer nas suas reflexões seminais sobre o Mito quer na sua obra póstuma sobre o totalitarismo de Estado ${ }^{16}$, as dimensões ideológicas que se geram em torno de modalidades de apreensão perceptivas indiferenciadas.

A exploração de uma sensibilidade primária, penetrada pelas vivências da superfície dos objectos criados e desligada de eixos interpretativos absolutos, faz parte da base programática das formas artísticas vanguardistas. A criação artística modernista deixa-se caracterizar pela sua abertura ao indeterminado, já que, privilegiando uma apreensão polissémica dos seus objectos, confronta a sensibilidade do espectador com elementos estéticos emergentes - isto é, que surgem desligados de uma teleologia estrutural da obra. E é também aqui que encontramos uma especificidade do fisiognómico, a saber: os traços fisiognómicos opõem-se aos traços mnésicos das operações cognitivas. Tal como se depreende da des-figuração instituída pela pintura modernista, o robustecimento da sensibilidade ocorre, em larga medida, através da suspensão de uma apreensão estética mapeada pela memória. Ainda ao nível da observação da obra de arte, já o contrário vale como máxima: quanto maior o invólucro interpretativo, tanto menor a pregnância fisiognómica.

${ }^{15}$ CASSIRER, Ernst, op. cit., p. 232-233. Por aqui se vê que, embora Cassirer utilize o exemplo de uma simples linha para demonstrar o conceito de "pregnância simbólica" - o que, à primeira vista, poderia sugerir mais um caso de redução visual caracterológica -, a intenção do filósofo é a de mostrar as várias possibilidades de sentido que se abrem à percepção. Pela sua natureza não-essencialista, a "linha ornamental" cassireriana distingue-se, assim, das "linhas silhuéticas" de Lavater e da "linha da beleza" de Hogarth. Sobre as várias articulações de sentido que atravessam a linha ornamental, vide BRAGA, Joaquim, Die symbolische Prägnanz des Bildes. Zu einer Kritik des Bildbegriffs nach der Philosophie Ernst Cassirers, Freiburg, Centaurus Verlag, 2012, pp. 113-126.

${ }^{16}$ CAssirer, Ernst, Vom Mythus des Staates, Übers. von Franz Stoessel, Hamburg, Felix Meiner Verlag, 2002. 


\section{Acoplamentos atmosféricos e intensificação do sensível}

Enquanto a fisiognomia ideológica faz do "carácter" o seu conceito central, já a fisiognomia estético-artística, afastando-se da aisthesis moralis, privilegia o conceito de "atmosfera". Esta mudança é significativa. Desde logo porque, a nível teórico, o conceito de atmosfera vem favorecer uma melhor especificação do conceito de "fisiognómico". Naquilo que representam para a pretensa objectivação do carácter humano, as silhuetas lavaterianas são já um sinal sintomático das dimensões atmosféricas geradas pelos processos fisiognómicos. A utilização das formas silhuéticas visa, nesse sentido, enfraquecer a densidade das informações visuais e ultrapassar a impossibilidade de se apartar destas traços caracterológicos inequívocos. Sendo a atmosfera um dos efeitos mais acentuados das modalidades da percepção fisiognómicas, ela não se relaciona com os eventos sensíveis através de uma função simbólica contrastiva, mas antes indexicálica. O atmosférico desempenha uma dupla função perceptiva inclusiva, isto é, confere aos objectos e eventos da percepção um campo de observação situado, ao mesmo tempo que contribui para a inserção do sujeito cognoscente dentro desse campo de observação. No entanto, a indiferenciação cognitiva resultante dos acoplamentos atmosféricos entre sujeito e objecto não encerra uma negação dos traços distintivos entre atmosferas. A atmosfera do evento $x$ diferencia-se da atmosfera do evento $y$. É somente a este nível de comparação que podemos dizer que as atmosferas formam traços mnésicos, que entram, por sua vez, nos processos de individuação dos eventos sensíveis.

É graças à edificação de um campo de observação, onde as experiências perceptuais são localizadas e articuladas e ao qual os mecanismos de atenção se enlaçam, que os processos semiósicos de selecção e retenção das informações sensoriais se tornam possíveis e inteligíveis. ${ }^{17}$

${ }^{17}$ Atmosferas resultantes de eventos (ou objectos) com uma grande carga afectiva podem inibir, de forma substancial, a estruturação de níveis de significação diferenciados e, por consequência, comprometer o despontar dos processos semiósicos. E, também, não é por acaso que a esses eventos estejam associadas expressões interjectivas - como, por exemplo, "Inacreditável!", "Impensável!", "Inexplicável!". Por sua vez, a concordância de percepção e expressão - isto é, neste caso, a continuidade fisiognómica traçada entre sensibilidade e signo - incrementa, ainda mais, o grau de intraduzibilidade psíquico dos eventos. 
Tal edificação evidencia, desde logo, um processo proto-semiósico. Embora as descrições expressivas sobre as impressões ambienciais da nossa percepção nos levem a compreender o atmosférico como um estádio interpretativo subsequente - logo, meramente descritivo -, o que ocorre, porém, é a sua anteposição ao juízo interpretativo; anteposição essa marcada pela manifestação de qualidades sensíveis emergentes que nunca chegam a entrar, totalmente, na consciência do intérprete. (As técnicas geradoras de atmosferas "publicitárias" e "propagandísticas" exploram, de forma continuada, esses intervalos da consciência).

Porém, a qualificação do atmosférico como processo proto-semiósico ultrapassa a indexicalidade inicial de sujeito e objecto. É certo que os acoplamentos atmosféricos desencadeiam conexões espácio-temporais que envolvem o espectador dentro dum determinado campo de observação. Contudo, apesar desta imanência indexicálica, é propriedade do atmosférico conferir aos objectos e eventos dimensões sensíveis que transcendem a sua condição física, o seu hic et nunc. Dizer isto significa pressupor que o atmosférico potencializa a expressão sensível $^{18}$ dos objectos e eventos, confere-lhes uma cognoscibilidade excessiva - ou, nas palavras de Mikel Dufrenne, «incomensurável» ${ }^{19}-$, que transborda a sua própria materialidade. Os processos estético-artísticos acusam a existência do objecto transbordante gerado pela obra de arte. Sem uma conjuntura de descolagem do "aqui e agora" da obra, ao qual a sua superfície de inscrição está materialmente votada, dificilmente se incrementariam as bases fundamentais para os seus processos de simbolização.

\section{Do imersivo no atmosférico}

A individuação do atmosférico passa pela sua potenciação como motivo pictórico - isto é, como objecto icónico central - e não como

${ }^{18}$ Convém referir que, neste aspecto, o "sensível" não exclui a existência de outras modalidades atmosféricas. Há atmosferas "mentais", isto é, desencadeadas por objectos do pensamento e da imaginação, que podem ser geradoras de ressonâncias e manifestações somáticas.

${ }^{19}$ Dufrenne, Mikel, The Phenomenology of Aesthetic Experience, Trans. Edward Casey et al., Evanston, Northwestern University Press, 1973, p. 183. 
mero adorno figurativo. A pintura de paisagem foi, nesse aspecto, um estádio relevante para tal processo de individuação. Sob o ponto de vista conceptual, o conceito de "paisagem" é, essencialmente, uma construção da arte pictural. Há nele, como em muitas formas pictóricas, uma evolução relevante que tem como ponto-chave a emancipação do "fundo" face à "figura"; emancipação essa que, ao mesmo tempo, assinala um certo primado da expressão sobre a representação. Veja-se, por exemplo, a picturalidade paisagística de William Turner. O gesto artístico de Turner oferece-nos, de forma exemplar, a ampliação do atmosférico a partir da sua génese fisiognómica. Quando, em certas obras de Turner, os traços se fazem manchas de cor e luz, a percepção do espectador é confrontada com o espectro virulento da impressão total gerada pelo atmosférico. Deixando de haver, dentro da tela, traços fisiognómicos individualizados - impostos, por exemplo, pela figuração - , as modalidades perceptivas fisiognómicas ficam imediatamente ligadas a uma explosão irrefreável (porque total) da própria picturalidade. É sabido que o efeito paisagístico é gerado através de uma articulação de elementos sensoriais que, podendo ou não ter afinidades materiais entre si, são levados a integrar uma configuração expressiva emergente. E isso significa: o eclipse de um dos elementos integrados transforma $o$ todo do qual faz parte.

Ora, como é exemplar no caso da arte pictural, a não fragmentação do todo e a sua consequente repercussão sensorial invertem, de forma decisiva, as operações que estão na base da relação "observador-observado". Se quisermos ilustrar este facto, basta acrescentar a Turner o nome de Caspar David Friedrich, para compreendermos como é que um dos maiores vultos da pintura do século vinte, Mark Rothko, criou o dispositivo pictórico que impera nas suas obras. A picturalidade paisagística de ambos concorreu, em muito, para que Rothko formulasse a ideia do "estar dentro da imagem", tanto na sua produção quanto na sua recepção. E, na génese desta ideia, encontra-se o facto de as atmosferas gerarem e viverem de um efeito imersivo. A indiferenciação entre as partes e o todo é alimentada por um impulso fisiognómico que tem a capacidade de retardar o aparecimento de uma observação categorial, através da qual é possível estabelecer um marco de distância relativamente ao fenómeno observado. O mesmo é dizer, o grau de indistinção imposto à relação observador-observado - tal como pretendia Rothko redunda numa vivência imersiva, como se o primeiro estivesse dentro do 
segundo. No centro óptico das formas imagéticas clássicas, os detalhes figurativos levam o olhar a percorrer uma sequencialidade narrativa, esbatendo-se, assim, a impressão atmosférica da superfície pictórica. Tanto nas obras de C. D. Friedrich como nas de Turner, essa impressão é recuperada e, simultaneamente, elevada à condição de motivo icónico principal. A época de Rothko apresenta outros desafios à reinvenção sensível do atmosférico. Um deles é puramente material. Ao artista vanguardista não será indiferente o olhar de um observador cada vez mais educado pelas reproduções imagéticas miniaturais - logo, por assim dizer, tendencialmente insensível à articulação espacial "distância-proximidade" que se joga dentro do espaço físico museológico. Por isso, é possível ver na importância dada à ampliação da superfície de inscrição pictórica uma resposta material (mas com efeitos estéticos categóricos) ao enclausuramento óptico da percepção.

No entanto, e apesar do seu percurso individuante, convém referir que o atmosférico é, ainda hoje, remetido para a estruturação do fundo de inscrição de certas configurações mediais. Na era dos meios digitais, as background pictures são uma presença normal em qualquer super-médium tecnológico. Mas, na arte, foi Richard Wagner que intentou fazer delas um instrumento necessário para objectivar o super-médium da pretensa "obra de arte total". O Gesamtkunstwerk somente é realizável graças a uma configuração conjunta e dramática dos diversos médiuns envolvidos, sendo, nessa exacta medida, a imagem pictural aquele médium que, na hierarquia determinada por Wagner, estabelece o próprio fundo (cenográfico, neste caso) do super-médium. Há, aqui, um efeito quase causal entre super-médium e espaço de inscrição da imagem, pois, para que outros médiuns sejam incluídos numa superfície única, torna-se necessário fazer "recuar" a imagem. Ela deixa de ocupar o lugar de figura e fica circunscrita ao lugar de fundo. Que a pintura paisagística seja o género pictórico escolhido por Wagner para preencher o fundo da obra de arte total, não é por mero acaso. A ela se refere Wagner como "fundo da natureza", ${ }^{20}$ porque restitui ao homem o seu fulgor individual. Todavia, as razões antropológicas e caracterológicas não são as únicas que atestam da sua relevância para a configuração do super-médium wagneriano.

${ }^{20}$ WaGner, Richard, Das Kunstwerk der Zukunft, Leipzig, Verlag von Otto Wigand, 1850, p. 182. 
A nível sensorial, sobrevém um efeito imersivo dado pela atmosfera paisagística, que é, na sua aplicabilidade estética, importado para o centro do espaço cénico. A unidade sensível do super-médium depende, em muito, da imagem de fundo preencher as descontinuidades materiais entre os vários médiuns envolvidos no Gesamtkunstwerk. E Wagner relata este preenchimento como um verdadeiro deslocamento da imagem museológica, encerrada na moldura da tela, para a figuração dramática do espaço cénico - sendo este, agora, a ampla moldura da imagem.

As extensões do conceito de "fisiognómico", bem como a sua ambiguidade semântica, podem ser seguidas desde o momento da redução caracterológica até ao momento da ampliação atmosférica. Este percurso, não sendo empiricamente linear, mas apenas puramente conceptual, revela-se-nos fundamental para a compreensão da geração e mutação de dispositivos imagéticos. Por um lado, somos confrontados com a redefinição estética da picturalidade através da potenciação das vivências fisiognómicas atmosféricas. Por outro lado, com o desenvolvimento das novas tecnologias digitais, assistimos a uma espécie de retrogradação da picturalidade face à integração de vários médiuns numa única superfície de inscrição gráfica. Se, no estádio ideológico do fisiognómico, há uma redução visual da picturalidade em prol da imposição caracterológica, no mundo das imagens digitais - nomeadamente aquelas para uso publicitário e propagandístico - há, pelo contrário, um incremento da utilização do visual através dos seus efeitos imersivos. Tal como sucede na construção do super-médium wagneriano, as imagens digitais possuem, na maior parte das vezes, uma função imersiva. Articulada com outros médiuns, cumpre à imagem recriar o fundo visual da superfície de inscrição gráfica. Mas este fundo visual não possui uma função puramente ilustrativa, como se verifica em certas configurações intermediais. Uma observação mais rigorosa poder-nos-á mostrar que a unidade sensível do super-médium - concretamente, a expressão material da sua superfície de inscrição - depende, em muito, da função imersiva que a picturalidade nele desempenha. $\mathrm{O}$ imagético como fundo visual concorre para a desfragmentação dos segmentos materiais que cada médium exibe no espaço de inscrição do super-médium, já que, formando um campo perceptual primário estável, contribui directamente para a articulação das informações sensoriais que resultam de cada médium envolvido, tornando assim possível uma melhor apreensão dos conteúdos semânticos veiculados pelas mesmas. 


\section{Conclusão}

Um dos traços distintivos da arte moderna vanguardista é a elevação da obra artística a um mundo sensível contrastivo. Sendo um mundo diametralmente oposto ao dos fenómenos da percepção quotidiana, visto que a uniformidade das informações sensoriais é preterida a favor da sua heterogeneidade, as sensações tendem a imperar nos processos de apreensão e significação dos objectos estético-artísticos. As teorias estéticas sobre a arte têm vindo a prestar mais atenção a essa ideia de contraste, destacando, muitas vezes, a natureza espectral de certas configurações artísticas e a multiplicidade de interpretações a que estão sujeitas. Mas é também aí, nessa afirmação radical do múltiplo face ao uno, que desponta a concepção teórica de a reflexão estética se ater apenas aos aspectos "informais" que envolvem a criação e a recepção da obra de arte. Com isso, e paradoxalmente, depressa se esvanecem os elementos contrastivos entre percepção estético-artística e percepção quotidiana, ficando a obra irremediavelmente votada à condição de "objecto entre objectos". Gernot Böhme, por exemplo, apresentou a proposta de transformar a reflexão estética no estudo do atmosférico ${ }^{21}$. O problema que sobrevém de tal proposta coloca-se em relação à praxis artística e aos seus objectos, uma vez que ficariam meramente reduzidos às modalidades da percepção fisiognómicas. Seguir Böhme significaria circunscrever as dimensões estéticas da experiência a um mero presentismo existencial, pondo, por conseguinte, em causa as dinâmicas de transformação inerentes ao património de conhecimento adquirido pelo espectador da arte. ${ }^{22}$ Tal como referimos anteriormente, as dimensões atmosféricas de uma obra contribuem, em muito, para a estruturação do seu estatuto sensível singular, mas, no âmago da experiência estético-artística, confluem quase sempre vivências e inscrições mnésicas auto-referenciais que, provindas de processos semiósicos diferenciadores, a excluem de outras formas simbólicas e a incluem no mundo da arte.

${ }^{21}$ BöHme, Gernot, Atmosphäre. Essays zur neuen Ästhetik, Frankfurt am Main, Suhrkamp Verlag, 1995.

${ }^{22}$ Uma crítica às pretensões de Böhme e ao seu conceito de Atmosphäre pode ser encontrada em SEel, Martin, Ästhetik des Erscheinens, Frankfurt am Main, Suhrkamp Verlag, 2003, pp. 152-156. 